\title{
Research Article \\ Efficacy of Nonthermal Atmospheric Pressure Plasma for Tooth Bleaching
}

\author{
Seoul Hee Nam, ${ }^{1}$ Hae June Lee, ${ }^{2}$ Jin Woo Hong, ${ }^{3}$ and Gyoo Cheon Kim ${ }^{1}$ \\ ${ }^{1}$ Department of Oral Anatomy, School of Dentistry, Pusan National University, Yangsan 626-870, Republic of Korea \\ ${ }^{2}$ Department of Electrical Engineering, Pusan National University, Busan 609-735, Republic of Korea \\ ${ }^{3}$ Department of Internal Medicine, School of Korean Medicine, Pusan National University, Yangsan 626-870, Republic of Korea
}

Correspondence should be addressed to Jin Woo Hong; jwhong@pusan.ac.kr and Gyoo Cheon Kim; ki91000m@pusan.ac.kr

Received 15 October 2014; Revised 2 December 2014; Accepted 2 December 2014

Academic Editor: Serdar Üşümez

Copyright ( 2015 Seoul Hee Nam et al. This is an open access article distributed under the Creative Commons Attribution License, which permits unrestricted use, distribution, and reproduction in any medium, provided the original work is properly cited.

\begin{abstract}
The conventional light source used for tooth bleaching has the potential to cause thermal damage, and the actual role of the light source is doubtful. In this study, we evaluated bleaching efficacy, temperature, and morphological safety after tooth bleaching with nonthermal atmospheric pressure plasma. Tooth bleaching combined with plasma had improved efficacy in providing a higher level of brightness. The temperature of the pulp chamber was maintained around $37^{\circ} \mathrm{C}$, indicating that the plasma does not cause any thermal damage. The morphological results of tooth bleaching with plasma did not affect mineral composition under scanning electron microscopy (SEM) observations. On the basis of these results, the application of plasma and low concentration of $15 \%$ carbamide peroxide (CP) has a high capability for effective tooth bleaching. It can be documented that plasma is a safe energe source, which has no deleterious effects on the tooth surface.
\end{abstract}

\section{Introduction}

The demand for an improved appearance and a whiter smile has made tooth bleaching a very popular dental procedure [1] . As tooth bleaching continues to grow in popularity, numerous patients seek dental assistance for cosmetic improvement of tooth discoloration.

Clinical bleaching agents use a high concentration of hydrogen peroxide $\left(\mathrm{HP} ; \mathrm{H}_{2} \mathrm{O}_{2}\right.$ ) or carbamide peroxide (CP; $\mathrm{CH}_{6} \mathrm{~N}_{2} \mathrm{O}_{3}$ ), both of which provide oxidative power [2]. They diffuse into and through enamel to reach dentin where they react with the organic chromogens responsible for the major color factors of teeth [3]. Most of the current in-office tooth bleaching techniques use a light source or heat as the activator to improve bleaching efficacy by accelerating the free radical $\left(\mathrm{HO}_{2}{ }^{\circ}, \mathrm{HO}^{\circ}\right)$ dissociation rate [4]. These free radicals have low molecular weights and are able to denature proteins, penetrate enamel, and diffuse through the organic matrix of dentin to exert their bleaching effect [5], thus reducing the time needed to whiten teeth [6].
However, tooth bleaching with a high concentration of HP bleaching agent and a high-intensity light source has the potential to cause adverse effects on the surface enamel $[7,8]$. Consequently, the bleached surfaces will incur greater or faster morphological and structural changes in enamel $[9,10]$. Furthermore, studies have demonstrated that the heat generated by the light sources used in tooth bleaching may also increase the temperature at the tooth surface and inside the pulp chamber [11,12]. It is commonly believed that such temperature increases associated with certain tooth bleaching procedures pose a serious threat to pulp vitality $[13,14]$.

Plasma is the fourth state of matter, the others being solid, liquid, and gas. Plasma forms when gas is ionized. It has the ability to conduct electricity and respond to electromagnetic fields, because plasma contains many radicals, a strong electric field, and charged particles. Since 2000, nonthermal atmospheric pressure plasma sources have been used for biomedical applications such as bacterial sterilization, cancer treatment, wound healing, and dental applications [15-18]. If plasma provides maximum efficiency in bleaching and safety, it can be widely used in dental clinics as a novel technique. 
Therefore, the aim of the present study was to demonstrate the bleaching efficacy and morphological effect of plasma with a low concentration of $15 \% \mathrm{CP}$.

\section{Materials and Methods}

2.1. Plasma Device. Figures 1(a) and 1(b) show a schematic of the nonthermal atmospheric pressure plasma and a photo of tooth bleaching using a microwave-driven plasma source. It was operated by a palm-sized power module with a net $2.5 \mathrm{~W}$ of input power. A low temperature plasma jet was driven by argon (Ar) gas with a flow rate of $2.5 \mathrm{~L} / \mathrm{min}^{-1}$ in air. The excited Ar species and/or energetic electrons from the plasma can make collisions with the ions, charged particles. The jet length extends up to $3 \mathrm{~cm}$ beyond the end of plasma device and the plasma jet can be touched without discomfort. The plasma diffused up to a few centimeters into the surrounding atmosphere to reach the tooth surface. A detailed description of the electrical and physical features of the plasma jet has reported this previously $[16,18]$.

2.2. Tooth Preparation. Twenty freshly extracted intact human teeth were stored in $0.4 \%$ sodium azide solution at room temperature until required. Any teeth with signs of fracture, dental caries, or structural anomalies were discarded. Before experimental use, all teeth were removed with a soft-tissue ultrasonic scaler and polished in a dental rubber cup with water or pumice slurry prophylaxis. The roots were cut with water-cooling using a diamond saw (Struers Minitom, Copenhagen, Denmark) approximately $0.5 \mathrm{~mm}$ below the cement-enamel junction. The crown was cut in half longitudinally and cut surfaces were coated with two layers of nail varnish. The study was approved by the Research Ethics Committee of the Pusan National University Yangsan Hospital, Yangsan, Republic of Korea (Approval number 04-2012-010).

2.3. Tooth Bleaching Procedure. Before the tooth bleaching, the buccal surface of each tooth was photographed using a digital-imaging system provided by a stereomicroscope (SZCTV, Olympus, Tokyo, Japan) at 10x magnification. The teeth were randomly assigned to two groups $(n=10)$. Group 1 received a $15 \%$ CP gel application which contained $5.4 \%$ HP (every $10 \mathrm{~min}$, Kool White 15\%, Pac-Dent International, Walnut, CA, USA) and plasma for $30 \mathrm{~min}$. The tip of the static plasma device was positioned at a $1 \mathrm{~cm}$ distance from the tooth surface. These bleaching procedures were repeated three times during 30 min treatment. Group 2 was treated with a uniform $1 \mathrm{~mm}$ layer of $15 \% \mathrm{CP}$ alone without plasma application. After $10 \mathrm{~min}$ application, the teeth were thoroughly rinsed to remove all the gel with distilled water and gently dried with sterile gauze. The procedure was repeated at $10 \mathrm{~min}$ intervals so that the total bleaching time was $30 \mathrm{~min}$.

2.4. Analysis of the Bleaching Efficacy. The tooth images were captured with a 10x magnification digital-imaging system consisting of a stereomicroscope connected to a camera (Pixel Link PL-B686 CU, Canada) at $10 \mathrm{~min}$ intervals. The images were loaded onto a computer through Image-Pro
Plus 5.1 software (Media Cybernetics Inc., Washington, DC, USA). The overall color changes $(\Delta E)$ were assessed on the basis of the Commission Internationale de L'Eclairage (CIE, 1979) Lab Color System [19]. The $L^{*}$ value represents the degree of lightness from 0 (black) to 100 (white). The $a^{*}$ value represents the degree of greenness (negative $a^{*}$ ) or redness (positive $a^{*}$ ), while the $b^{*}$ value represents the degree of blueness (negative $b^{*}$ ) or yellowness (positive $b^{*}$ ). The differences in $\Delta E$ values were calculated to compare the color changes and are expressed by the formula

$$
\Delta E=\sqrt{\left(\Delta L^{*}\right)^{2}+\left(\Delta a^{*}\right)^{2}+\left(\Delta b^{*}\right)^{2}} .
$$

2.5. Measurement of Tooth Temperature. The temperature increase in each tooth was measured independently from the tooth bleaching experiments using a fiber-optic temperature measurement system (FTI-10 fiber-optic signal conditioner, FOT-L-SD fiber-optic temperature sensor; FISO Technologies Inc., Quebec, Canada). The fiber-optic temperature sensor was located within the pulp chamber. The distance between the emitting tip of the plasma source and the fiberoptic temperature sensor was set at $1 \mathrm{~cm}$ during "plasma-on" for $30 \mathrm{~min}$ at room temperature $\left(25^{\circ} \mathrm{C}\right)$.

2.6. Surface Morphology. Immediately after drying, the images were then assessed using scanning electron microscopy (SEM; S3500N, Hitachi Co., Tokyo, Japan) at $15 \mathrm{kV}$ accelerating voltage. The images were then assessed at $2,000 \mathrm{x}$ magnification.

2.7. Statistical Analysis. Statistical analysis was performed with the SPSS computer program (SPSS Inc., Version 18.0, Chicago, IL, USA). Student's $t$-test was used to determine the difference in $\Delta E$ values between tooth bleaching with plasma and that without plasma. The level of significance was defined at $P<0.05$.

\section{Results and Discussion}

3.1. Bleaching Efficacy. Today's bleaching systems are the result of efforts to increase patient benefits in terms of better bleaching efficacy and ease of use [20]. Various light sources are being used in dental clinics, as they are known to reduce the total treatment time; however, the bleaching effects caused by such light sources remain unclear [21]. This study was conducted using nonthermal atmospheric pressure plasma as a light source to solve several problems associated with current tooth bleaching methods. Tooth bleaching efficacy using plasma plus 15\% CP significantly increased during the 30 min treatment. Plasma produces a larger amount of hydroxyl radicals $\left({ }^{\circ} \mathrm{OH}\right)$ [16] which play an important role in tooth bleaching. Hence, there is synergistic enhancement resulting in a more rapid bleaching efficacy. Nam et al. [22] have reported that plasma application resulted in more improved tooth bleaching than in conventional methods. In this study, Table 1 reveals that there was a statistically significant difference in the bleaching efficacy between Group 1 and Group $2(P<0.05)$. The mean $\Delta E \pm$ standard deviation 
TABLE 1: The mean $\Delta E \pm$ SD after tooth bleaching with and without plasma and $P$ values using Student's $t$-test.

\begin{tabular}{|c|c|c|c|c|c|}
\hline \multirow{2}{*}{ Observation times } & \multirow{2}{*}{ Bleaching agents } & \multirow{2}{*}{$N$} & \multicolumn{2}{|c|}{ Mean $\Delta E \pm \mathrm{SD}$} & \multirow{2}{*}{$\begin{array}{c}t \text {-test } \\
P \text { values }\end{array}$} \\
\hline & & & Plasma & Without plasma & \\
\hline $10 \mathrm{~min}$ & $15 \% \mathrm{CP}$ & 20 & $17.82 \pm 1.74$ & $5.87 \pm 0.81$ & $0.000^{*}$ \\
\hline $20 \mathrm{~min}$ & $15 \% \mathrm{CP}$ & 20 & $23.48 \pm 2.30$ & $6.98 \pm 0.93$ & $0.000^{*}$ \\
\hline $30 \mathrm{~min}$ & $15 \% \mathrm{CP}$ & 20 & $29.91 \pm 1.74$ & $8.30 \pm 1.15$ & $0.000^{*}$ \\
\hline
\end{tabular}

$\mathrm{CP}$ : carbamide peroxide, $\triangle E$ : overall color changes, and SD: standard deviation.

${ }^{*} \Delta E$ values show significant differences between the two groups $(P<0.05)$.

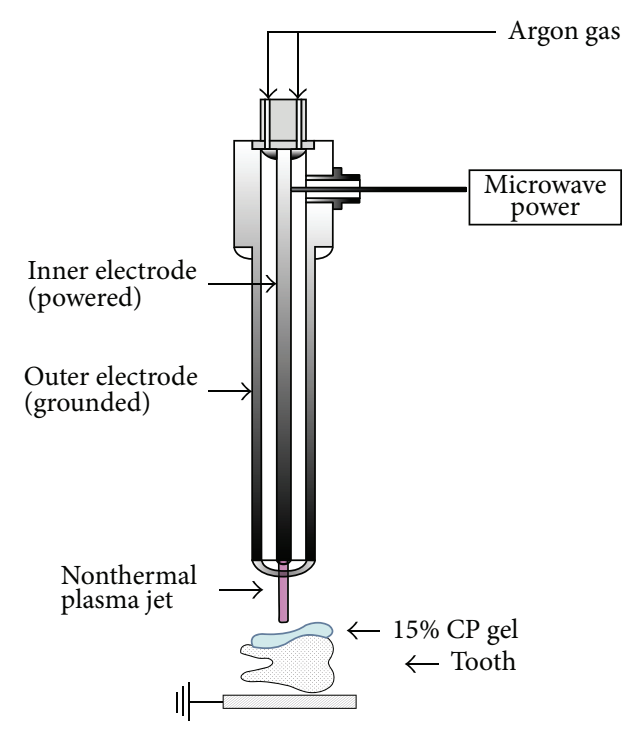

(a)

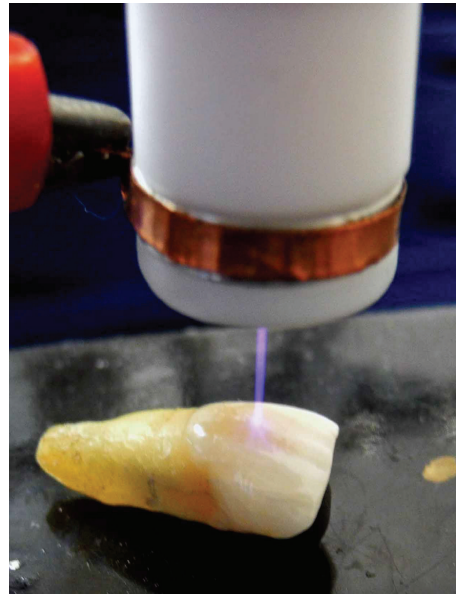

(b)

FIGURE 1: The application of nonthermal atmospheric pressure plasma for tooth bleaching with low concentrations of $15 \%$ CP. (a) The plasma device and (b) the process during bleaching treatment.

(SD) after 30 min bleaching was $29.91 \pm 1.74$ (Group 1) and $8.30 \pm 1.15$ (Group 2). Group 1A was 3.7 times brighter than Group 1B. The teeth treated with plasma showed higher $\Delta E$ values than those without plasma. Remarkable color change occurred over time in the group treated with plasma. These results suggest that the amount of ${ }^{\bullet} \mathrm{OH}$ generated from plasma diffuses quickly through the surface of the enamel and breaks down the conjugated bonds in protein chains (stains) into a single bond, which increases bleaching efficacy.

3.2. Temperature Measurement. Many studies have demonstrated thermal damage induced by light sources. It is also known that temperature increases in the pulp chamber may be a serious threat to the vitality of the pulp [23]. Eriksson et al. [24] showed that pulp temperatures in excess of $42.5^{\circ} \mathrm{C}$ may induce irreversible pulpitis. In conventional bleaching procedures, temperatures can easily exceed these values [22]. However, the temperature of a tooth treated with plasma did not increase above body temperature. The plasma took about $10 \mathrm{~min}$ to reach a steady-state temperature, and thereafter the temperature was continuously maintained around $37^{\circ} \mathrm{C}$ throughout the bleaching duration (Figure 2).

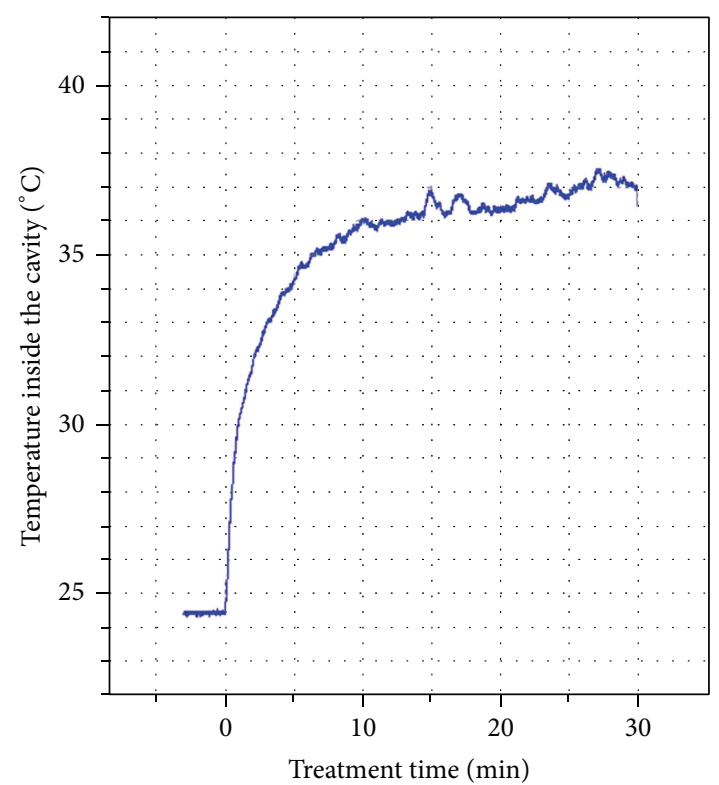

FIGURE 2: Measurement of the dental cavity temperature during the bleaching treatment. 


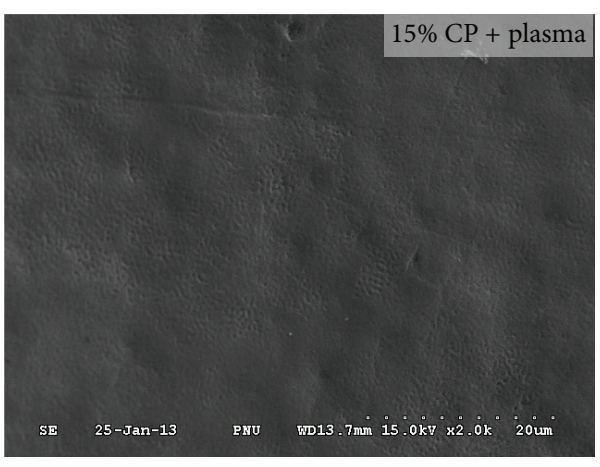

(a)

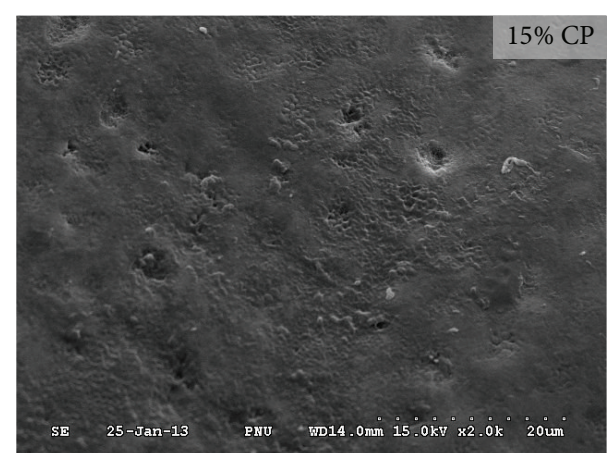

(b)

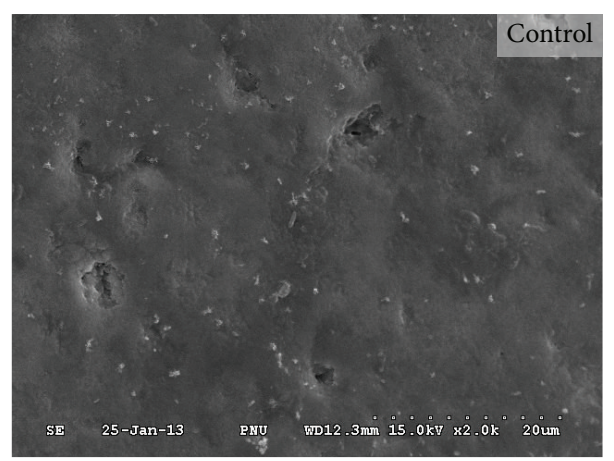

(c)

FIGURE 3: SEM photomicrographs of enamel surface morphology for each group at 2000x magnification.

Due to the fact that the temperature of plasma treatment is similar to human body temperature, therefore, it can be concluded that plasma maintains a low and consistent pulp temperature during tooth bleaching and avoids undue risk to the pulp.

3.3. Tooth Surface Evaluation. In most cases, SEM studies were used to analyze the morphological changes of the tooth surface at high resolution and magnification [25]. According to a study by $\mathrm{Fu}$ et al. [26], bleached enamel surfaces resulted in morphological changes to the tooth surface. Figure 3 shows SEM photomicrographs of tooth enamel surfaces bleached with or without plasma. After combining plasma with a low concentration of $15 \% \mathrm{CP}$, the bleached enamel surface was observed to be smooth. On the other hand, the enamel surface treated with 15\% CP alone results in a much rougher surface than the control. The results of this study show that tooth bleaching with plasma does not cause morphological changes to tooth enamel. The tooth surface, in fact, remains smooth. This could explain how plasma effectively removes colored proteins [16, 27]. Plasma application for tooth bleaching does not dissolve the mineral content of tooth enamel, indicating that plasma did not influence the demineralization effects of bleached teeth. Based on the results of this study, the application of plasma for tooth bleaching quickly decomposed $\mathrm{HP}$ to ${ }^{\circ} \mathrm{OH}$ radical; thereby it did not cause the deleterious effects on enamel surface.

\section{Conclusions}

The combination of nonthermal atmospheric pressure plasma with $15 \% \mathrm{CP}$ has a greater capability for effective tooth bleaching than conventional light sources. The tooth surface temperature was maintained around $37^{\circ} \mathrm{C}$, indicating that the plasma does not cause any thermal damage to the tooth. The application of plasma did not cause any structural changes to the bleached surface. Nonthermal atmospheric pressure plasma has been proven to have no deleterious effect on bleached enamel. Therefore, tooth bleaching techniques using plasma represent a method of cosmetic dentistry with many practical applications in the future.

\section{Abbreviations \\ SEM: Scanning electron microscopy \\ CP: Carbamide peroxide.}

\section{Conflict of Interests}

The authors declare that there is no conflict of interests regarding the publication of this paper.

\section{Authors' Contribution}

Jin Woo Hong and Gyoo Cheon Kim contributed equally to this work. 


\section{Acknowledgment}

This work was supported by a 2-Year Research Grant of Pusan National University.

\section{References}

[1] G. A. Crim, "Prerestorative bleaching: effect on microleakage of Class V cavities," Quintessence International, vol. 23, no. 12, pp. 823-825, 1992.

[2] C. J. Tredwin, S. Naik, N. J. Lewis, and C. Scully, "Hydrogen peroxide tooth-whitening (bleaching) products: review of adverse effects and safety issues," British Dental Journal, vol. 200, no. 7, pp. 371-376, 2006.

[3] A. Joiner, "The bleaching of teeth: a review of the literature," Journal of Dentistry, vol. 34, no. 7, pp. 412-419, 2006.

[4] K. Kawamoto and Y. Tsujimoto, "Effects of the hydroxyl radical and hydrogen peroxide on tooth bleaching," Journal of Endodontics, vol. 30, no. 1, pp. 45-50, 2004.

[5] G. Sun, "The role of lasers in cosmetic dentistry," Dental Clinics of North America, vol. 44, no. 4, pp. 831-850, 2000.

[6] C. T. Hanks, J. C. Fat, J. C. Wataha, and J. F. Corcoran, "Cytotoxicity and dentin permeability of carbamide peroxide and hydrogen peroxide vital bleaching materials, in vitro," Journal of Dental Research, vol. 72, no. 5, pp. 931-938, 1993.

[7] V. Cavalli, C. A. G. Arrais, M. Giannini, and G. M. B. Ambrosano, "High-concentrated carbamide peroxide bleaching agents effects on enamel surface," Journal of Oral Rehabilitation, vol. 31, no. 2, pp. 155-159, 2004.

[8] S. K. Al-Salehi, D. J. Wood, and P. V. Hatton, "The effect of $24 \mathrm{~h}$ non-stop hydrogen peroxide concentration on bovine enamel and dentine mineral content and microhardness," Journal of Dentistry, vol. 35, no. 11, pp. 845-850, 2007.

[9] N. C. Bitter, "A scanning electron microscope study of the longterm effect of bleaching agents on the enamel surface in vivo," General Dentistry, vol. 46, no. 1, pp. 84-88, 1998.

[10] J. O. Fugaro, I. Nordahl, O. J. Fugaro, B. A. Matis, and I. A. Mjör, "Pulp reaction to vital bleaching," Operative Dentistry, vol. 29, no. 4, pp. 363-368, 2004.

[11] A. U. Eldeniz, A. Usumez, S. Usumez, and N. Ozturk, "Pulpal temperature rise during light-activated bleaching," Journal of Biomedical Materials Research-Part B Applied Biomaterials, vol. 72, no. 2, pp. 254-259, 2005.

[12] W. Kabbach, D. M. Zezell, T. M. Pereira, F. G. Albero, V. R. G. Clavijo, and M. F. De Andrade, "A thermal investigation of dental bleaching in vitro," Photomedicine and Laser Surgery, vol. 26, no. 5, pp. 489-493, 2008.

[13] W. H. Bowles and Z. Ugwuneri, "Pulp chamber penetration by hydrogen peroxide following vital bleaching procedures," Journal of Endodontics, vol. 13, no. 8, pp. 375-377, 1987.

[14] M. Sulieman, "An overview of tooth discoloration: extrinsic, intrinsic and internalized stains," Dental Update, vol. 32, no. 8, pp. 463-464, 2005.

[15] G. Fridman, G. Friedman, A. Gutsol, A. B. Shekhter, V. N. Vasilets, and A. Fridman, "Applied plasma medicine," Plasma Processes and Polymers, vol. 5, no. 6, pp. 503-533, 2008.

[16] H. W. Lee, G. J. Kim, J. M. Kim, J. K. Park, J. K. Lee, and G. C. Kim, "Tooth bleaching with nonthermal atmospheric pressure plasma," Journal of Endodontics, vol. 35, no. 4, pp. 587-591, 2009.

[17] G. Lloyd, G. Friedman, S. Jafri, G. Schultz, A. Fridman, and K. Harding, "Gas plasma: medical uses and developments in wound care," Plasma Processes and Polymers, vol. 7, no. 3-4, pp. 194-211, 2010.

[18] S. K. Kang, M. Y. Choi, I. G. Koo et al., "Reactive hydroxyl radical-driven oral bacterial inactivation by radio frequency atmospheric plasma," Applied Physics Letters, vol. 98, no. 14, Article ID 143702, 2011.

[19] P. Villalta, H. Lu, Z. Okte, F. Garcia-Godoy, and J. M. Powers, "Effects of staining and bleaching on color change of dental composite resins," Journal of Prosthetic Dentistry, vol. 95, no. 2, pp. 137-142, 2006.

[20] J. O. Calatayud, P. M. de la Varga, C. O. Calatayud, and M. J. Calvo Box, "Comparative clinical study of two tooth bleaching protocols with $6 \%$ hydrogen peroxide," International Journal of Dentistry, vol. 2009, Article ID 928306, 5 pages, 2009.

[21] W. Buchalla and T. Attin, "External bleaching therapy with activation by heat, light or laser-a systematic review," Dental Materials, vol. 23, no. 5, pp. 586-596, 2007.

[22] S. H. Nam, H. W. Lee, S. H. Cho, J. K. Lee, Y. C. Jeon, and G. C. Kim, "High-efficiency tooth bleaching using nonthermal atmospheric pressure plasma with low concentration of hydrogen peroxide," Journal of Applied Oral Science, vol. 21, no. 3, pp. 265270, 2013.

[23] D. Oelgiesser, J. Blasbalg, and A. Ben-Amar, "Cavity preparation by Er-YAG laser on pulpal temperature rise," The American Journal of Dentistry, vol. 16, no. 2, pp. 96-98, 2003.

[24] A. Eriksson, T. Albrektsson, B. Grane, and D. McQueen, "Thermal injury to bone: a vital-microscopic description of heat effects," International Journal of Oral Surgery, vol. 11, no. 2, pp. 115-121, 1982.

[25] A. Joiner, "Review of the effects of peroxide on enamel and dentine properties," Journal of Dentistry, vol. 35, no. 12, pp. 889896, 2007.

[26] B. Fu, W. Hoth-Hannig, and M. Hannig, "Effects of dental bleaching on micro- and nano-morphological alterations of the enamel surface," The American Journal of Dentistry, vol. 20, no. 1, pp. 35-40, 2007.

[27] H. W. Lee, S. H. Nam, A.-A. H. Mohamed, G. C. Kim, and J. K. Lee, "Atmospheric pressure plasma jet composed of three electrodes: application to tooth bleaching," Plasma Processes and Polymers, vol. 7, no. 3-4, pp. 274-280, 2010. 


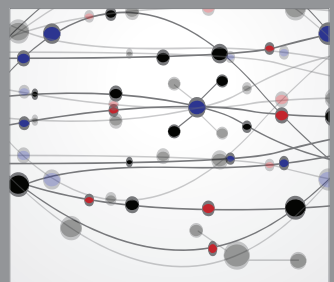

The Scientific World Journal
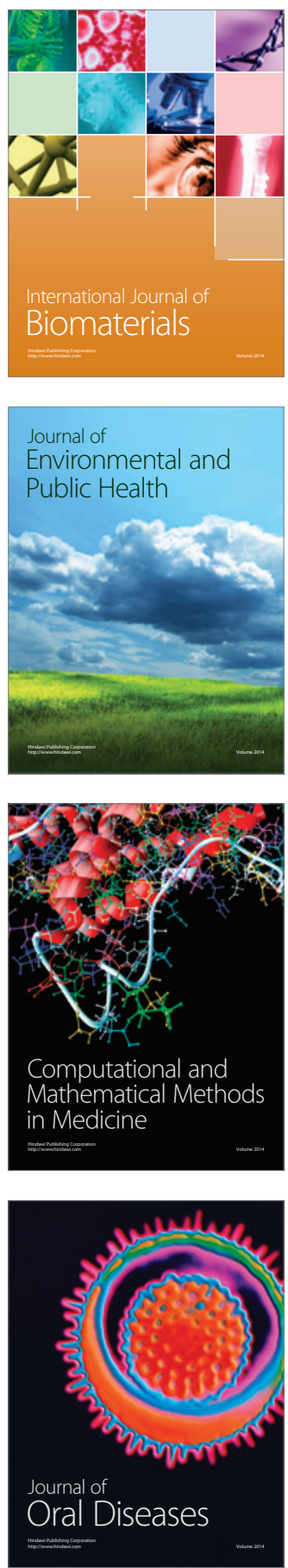
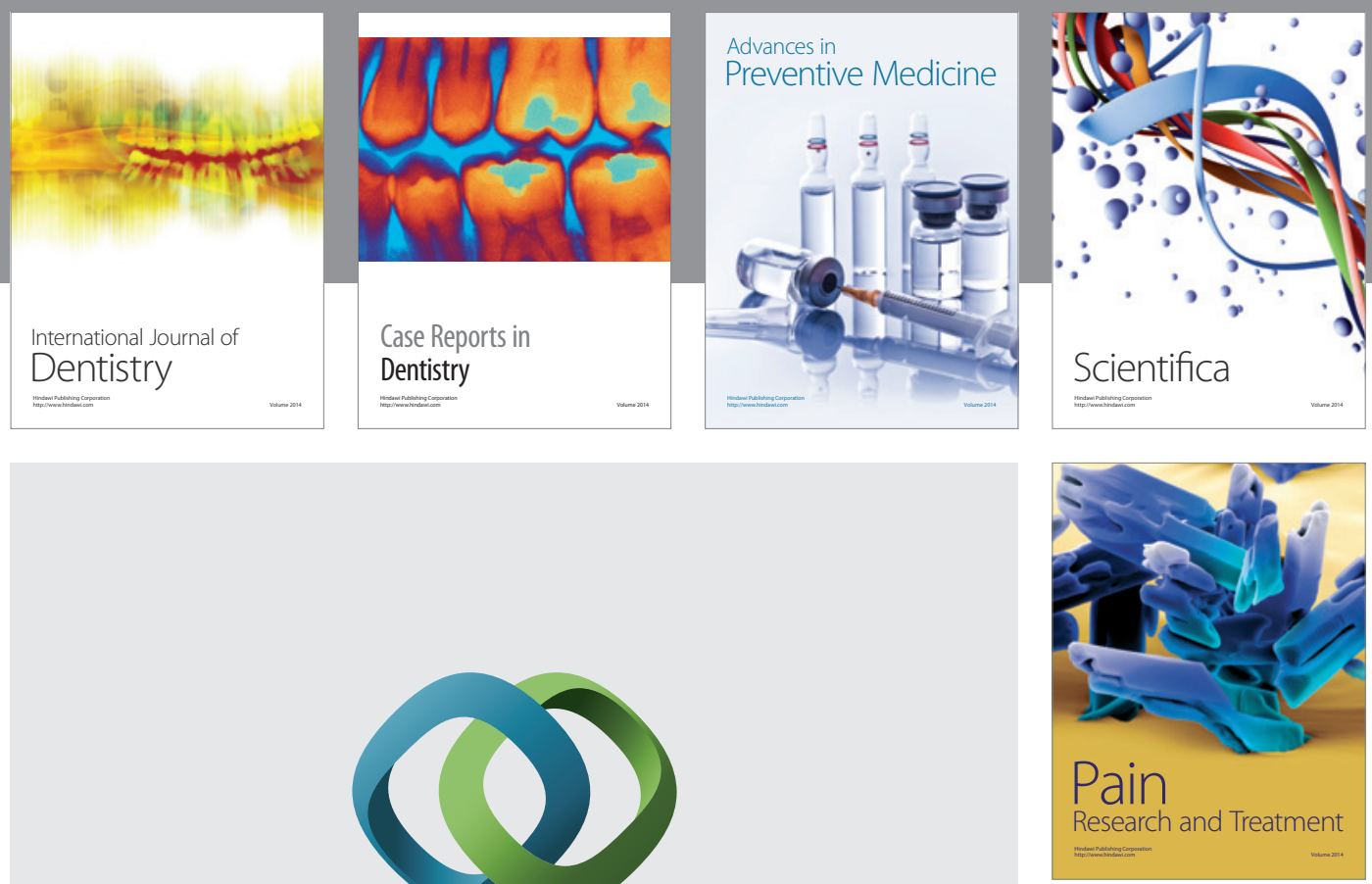

\section{Hindawi}

Submit your manuscripts at

http://www.hindawi.com
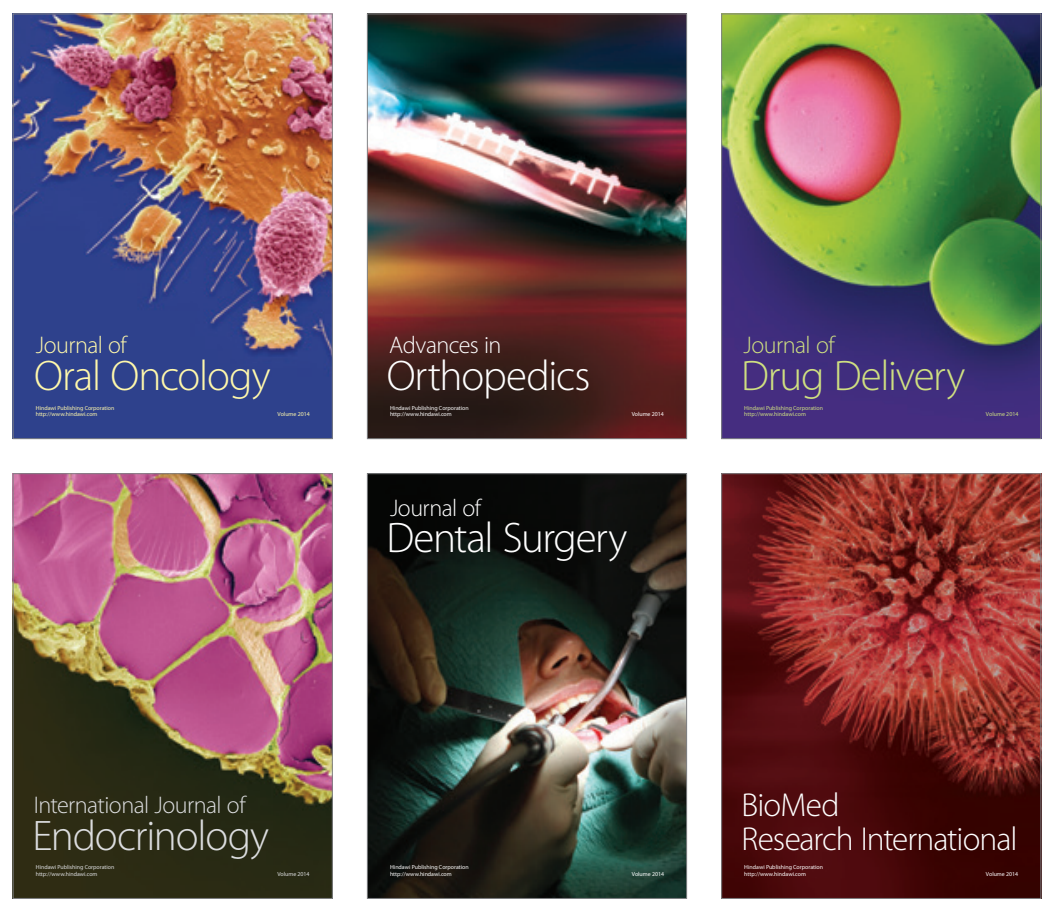

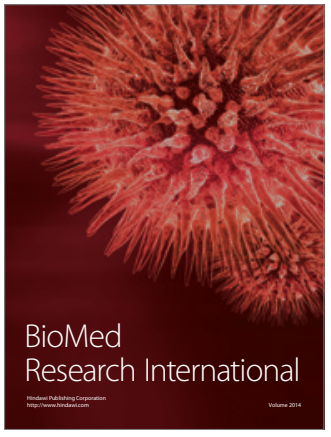

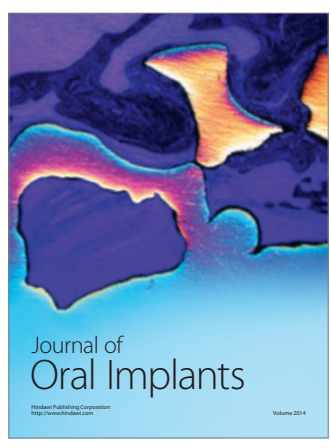
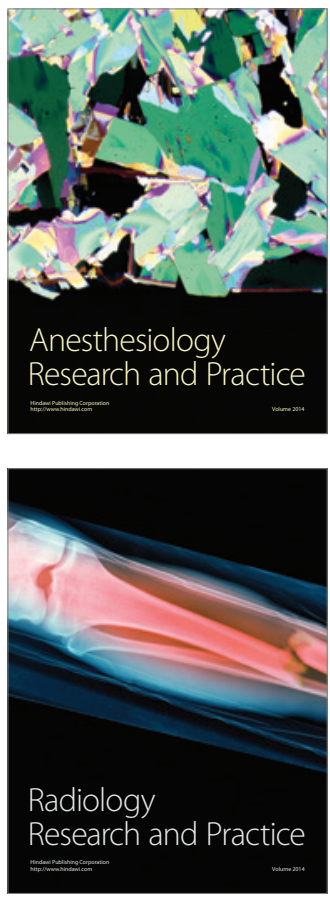